\title{
Adherence to Antiretroviral Therapy and Risk Factors Among MSM Patients in Hangzhou, China: A Cohort Study
}

\author{
Jinlei Zheng ${ }^{1}$, Lin Chen ${ }^{1}$, Guoxiang Zheng ${ }^{2}$, Lin $\mathrm{He}^{1}$, Yun Xu${ }^{1}$, Jun Jiang ${ }^{1}$, Mingyu Luo ${ }^{1}, \mathrm{Xiaohong} \mathrm{Pan}^{1}$, \\ Jianhua $\mathrm{Yu}^{2}$, Miaoying Dong² and Jiezhe Yang*1
}

${ }^{1}$ Zhejiang Provincial Center for Diseases Control and Prevention (Zhejiang CDC), Department of AIDS/STDs control and prevention, China

${ }^{2}$ Xixi hospital of Hangzhou, Infectious Department, China

*Corresponding author's: Jiezhe Yang, Zhejiang Provincial Center for Diseases Control and Prevention, Hangzhou, China. Mailing address: Zhejiang Provincial Center for Disease Control and Prevention, 3399 Binsheng Road, Hangzhou, Zhejiang 310051, P. R. China

\section{ARTICLE INFO}

Received: 蔧 July 25, 2019

Published: August 07, 2019

Citation: Jinlei Zheng, Lin Chen, Guoxiang Zheng, Lin He1, Yun Xu, Jun Jiang, Mingyu L, Xiaohong Pan, Jianhua Y, Miaoying Dong, Jiezhe Yang. Adherence to Antiretroviral Therapy and Risk Factors Among MSM Patients in Hangzhou, China: A Cohort Study. Biomed J Sci \& Tech Res 20(3)-2019. BJSTR. MS.ID.003443.

Keywords: Human Immunodeficiency Virus (HIV); Antiretroviral Treatment; Cohort Study

\begin{abstract}
This cohort study was to assess levels of adherence to antiretroviral therapy and the risky factors among HIV-positive Men who have sexed with men (MSM) in Hangzhou, China in 2015-2017. HIV-positive MSM who were 18 years of age or older and went to the clinic to initiate ART between Jan 2015 and Jun 2016 were recruited. Data were collected at baseline and at follow-up times of 1, 6, 12 months. The Generalized Estimating Equations (GEE) model was used to examine the risk factors of adherence. Among 397 individuals, $82.6 \%, 80.9 \%$ and $79.9 \%$ were fully adherent to the treatment at $1,6,12$ months of follow-up, respectively. In adjusted analyses, ART-initial CD4 cell count $(<500 \& \geq 500$ cells $/ \mathrm{mm}^{3}$ ) was not associated with ART adherence (Adjusted Risk Ratio [ARR] $=0.765$, $95 \% \mathrm{CI}=0.476-1.230$ ). Participants who were under 30 years of age and who used alcohol were associated with a higher risk of non-adherence (ARR=0.641, 1.809, 95\%CI=0.441$0.931,1.266-2.584)$. ART adherence was high among MSM as fellows. There was no effect of ART-initial CD4 cell count on adherence. Patients aged older and used alcohol need to be pay more attention.
\end{abstract}

\section{Introduction}

The prevalence of Human Immunodeficiency Virus (HIV) in Zhejiang province has increased substantially in the past three decades. The first case of HIV infection was reported in 1985 [1]. By the end of 2015, it was estimated that there was a cumulative total of 20,902 people living with HIV (PLWH) in Zhejiang province [2]. By the end of 2016, a total of 5,119 new HIV cases were reported in Zhejiang, and men who have sex with men (MSM) had the highest prevalence of HIV (6.92\%). Hangzhou has been affected by the epidemic with an HIV prevalence of $8.5 \%$ among MSM [3-4]. Zhejiang province launched a Free Antiretroviral Treatment Program (FARTP) in 2003 and has scaled the program up rapidly since the initiation of China's national FARTP in 2002.
More than $90 \%$ of HIV/ Acquired Immune Deficiency Syndrome (AIDS) patients accepted anti-retroviral therapy (ART) if they were diagnosed by 2016 [5-7].

The introduction of ART decreases both the individual and community viral load, reducing mortality and morbidity in HIVpositive patients [8-10]. Furthermore, benefits have been reported for the early detection and early use of ART, such as a reduced risk of HIV transmission, better immune recovery, and lower chance of developing HIV-related diseases [11-12]. Successful treatment largely depends on patient adherence to the ART. Various factors affecting ART adherence have been identified. The principal factors associated with non-adherence appear to be patient-related factors 
including alcohol and substance abuse [13]. One study has also stated other factors, such as pill burden and side-effects, depression, lack of family and social support, stigmatization and discrimination [14-15]. Despite the World Health Organization (WHO) guidance for early detection and early use of ART, assessing the benefits and drawbacks, such as side effects and long-term adherence, is always needed at the individual patient level. Few studies have discussed the impact of early ART-initial CD4 cell count on adherence, especially in developing countries.

The current study was undertaken by the infectious disease department in Xixi hospital in Hangzhou, Zhejiang province. All HIV/AIDS patients in Hangzhou are referred to the clinic to initiate the use of ART. Four full-time doctors and three nurses are available for treatment and follow-up. Our aim was to investigate the level of ART adherence and non-adherence among HIV-positive MSM in Hangzhou. We also evaluated the effect of early ART use on adherence over time while adjusting for other predictors.

\section{Materials and Methods}

\section{Study Population}

The study was conducted at Xixi hospital in Hangzhou. Patients were enrolled if they met the following criteria: MSM, were 18 years of age or older, if they had sex with a male in the last year, and if they lived in Hangzhou for at least half a year. Patients who would not provide their informed consent were excluded from the study. Figure 1 shows the subject selection procedure.

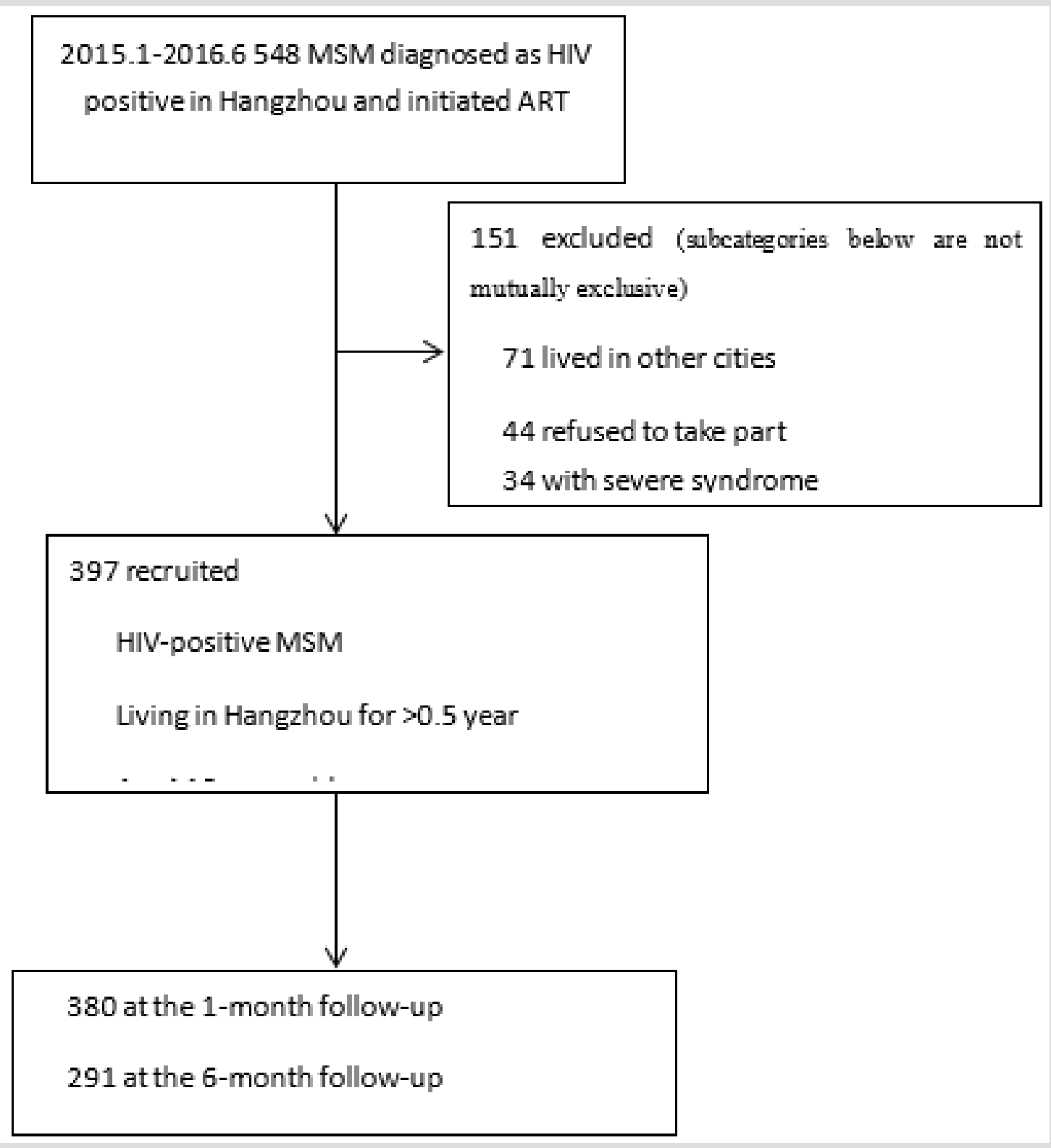

Figure 1: Study design flow chart for HIV/ AIDS cohort study 2015-2016. 


\section{Study Design}

The study was a prospective cohort study in Zhejiang province with continued enrollment of HIV-positive patients from Jan 2015 to Jun 2016. The HIV/AIDS clinic of Xixi hospital of Hangzhou was in charge of study recruitment. Enrollment was conducted when patients went to the clinic to initiate ART. A total of 397 patients were recruited in this study, and all completed the basic data collection. Self-designed questionnaire were validated based on pre-test among 10 HIV patients. Four-time surveys were complimented by doctors in clinic at one month of follow-up, six months of followup, twelve months of follow-up and sixteen months of follow-up, and questionnaires were filled out by doctors. Figure 1 shows that the follow-up rates were $95.7 \%, 73.2 \%$, and $77.6 \%$ for the 1 -month, 6-month, and 12-month follow-up points, respectively.

\section{Adherence Measures}

In this study, adherence to ART was calculated based on three items in a questionnaire completed by subjects during the followup visits. The three items were "Have you ever missed a dose of the drug in the last month?", "Have you ever taken the wrong drug in the last month?" and "Did you ever have a desire to stop taking the drug in the last month?". Patients responding to "yes" to any of the three questions were considered "sub-optimally adherent", whereas patients responding "no" to all three items were considered "adherent". Patients were also asked to report the reason for and frequency of missed doses/wrong doses/cessation of ART as well as possible factors.

\section{Other key variables}

Epidemiological data, such as age, education background, marriage, alcohol use, and sexual behavior were self-reported during follow-up survey. CD4+ T cell count were obtained from patient medical files at every follow-up.

\section{Statistical Analysis}

Statistical analyses were performed using SPSS statistical software (version 19.0). Descriptive statistics included mean, median,

\begin{tabular}{|c|c|c|c|c|c|c|}
\hline & Baseline & 1 month & 6 months & 12 months & $\chi^{2}$ & $\mathrm{P}$ \\
\hline \multicolumn{7}{|l|}{$\mathrm{Age}^{\mathrm{a}}$} \\
\hline \multirow{2}{*}{$<30$} & 65.7 & 66 & 69.7 & 66.6 & \multirow{2}{*}{1.371} & \multirow{2}{*}{0.712} \\
\hline & $(259 / 394)$ & $(249 / 377)$ & $(202 / 290)$ & $(203 / 305)$ & & \\
\hline \multirow{2}{*}{$\geq 30$} & 34.3 & 34 & 30.3 & 33.4 & & \\
\hline & $(135 / 394)$ & $(128 / 377)$ & $(88 / 290)$ & $(102 / 305)$ & & \\
\hline \multicolumn{7}{|c|}{ Education background ${ }^{b}$} \\
\hline \multirow{2}{*}{ Senior high school and under } & 31 & 30 & \multirow{2}{*}{$29.9(87 / 291)$} & 29.9 & \multirow{2}{*}{0.15} & \multirow{2}{*}{0.985} \\
\hline & $(123 / 397)$ & $(114 / 380)$ & & $(92 / 308)$ & & \\
\hline \multirow{2}{*}{ Greater than senior high school } & 69 & 70 & 70.1 & 70.1 & & \\
\hline & $(274 / 397)$ & $(266 / 380)$ & $(204 / 291)$ & $(216 / 308)$ & & \\
\hline Marriage $^{c}$ & & & & & & \\
\hline
\end{tabular}

frequency, and rate or proportion. Chi-square tests and trend chisquare tests were used to compare categorical variables. Generalized Estimating Equations models were used to explore possible associations between the dependent variable and independent variables. Crude risk ratios (CRR), adjusted risk ratios (ARR), and 95\% confidence intervals (CI) were calculated to evaluate the association between ART-initial CD4 cell counts and ART adherence. A p value less than 0.05 was considered statistically significant.

\section{Results}

Table 1 shows the comparison of sociodemographic characteristics at baseline and follow-up. No statistically significant differences in the distribution of age, education background, or marriage were found between participants at baseline and the 1-month, 6-month, and 12-month follow-up points (Table 1). $82.6 \%, 80.9 \%$ and $79.9 \%$ were fully adherent to the treatment at 1 -month, 6-months and 12-months after starting ART, respectively. There were no significant differences between the three groups for adherence rates $(\mathrm{P}>0.05)$. A significant difference was found in the number of missed doses, with rates of $13.7 \%, 16.8 \%, 19.2 \%$ at 1-month, 6-months, and 12-months, respectively (trend chisquare $=4.692, p=0.030$ ). The rate of taking the wrong medicine or stopping ART was lower than 5\% in follow-up, as shown in Table 2. The most common reasons for missed doses were forgetting to take the drug, which accounted for $53.3 \%, 59.6 \%, 65.5 \%$ of missed doses at 1-month, 6-months, and 12-months of follow-up, respectively. The second most commonly reported reason for missing doses was forgetting to carry the tablets, which accounted for $37.8 \%, 29.8 \%$, and $22.4 \%$ of missed doses at 1 -month, 6 -months, and 12 -months, respectively. AZT was the most commonly missed medicine, accounting for $11.0 \%(31 / 281), 15.8 \%(35 / 221), 18.6 \%(42 / 226)$ at 1-month, 6-months, and 12-months of follow-up, respectively. A Generalized Estimating Equations model was applied to explore the impact of ART-initial CD4 cell count on ART adherence, controlling for sociodemographic variables (age, education background), alcohol use, and anal sex as confounders. Table 1: Comparison of sociodemographic characteristics between subjects at baseline and follow-up. 


\begin{tabular}{|c|c|c|c|c|}
\hline \multirow{2}{*}{ Live together or married } & 24.7 & 25.1 & 24.1 & 26.1 \\
\cline { 2 - 4 } & $(98 / 396)$ & $(95 / 379)$ & $(70 / 291)$ & $(80 / 307)$ \\
\hline \multirow{2}{*}{ Divorced or single } & 75.3 & 74.9 & 75.9 & 73.9 \\
\cline { 2 - 5 } & $(298 / 396)$ & $(284 / 379)$ & $(221 / 291)$ \\
\hline
\end{tabular}

Missing data on age at baseline,1, 6, 12 months were 3,3,1,3, respectively;

Missing data on marriage at base-line,1,6,12 were 1,1,0,1, respectively;

Table 2: The change in adherence in last month of follow-up.

\begin{tabular}{|c|c|c|c|c|c|}
\hline & 1 month & 6 months & 12 months & $\chi^{2}$ & $P$ \\
\hline Adherence & & & & 0.857 & 0.651 \\
\hline Yes & $82.6(314 / 380)$ & $80.9(237 / 291)$ & $79.9(246 / 308)$ & & \\
\hline Non & $17.4(66 / 380)$ & $19.1(54 / 291)$ & $20.1(62 / 308)$ & & \\
\hline Missed taking drug & & & & 3.799 & 0.15 \\
\hline Yes & $13.7(52 / 380)$ & $16.8(49 / 291)$ & $19.2(59 / 308)$ & & \\
\hline No & $86.3(328 / 380)$ & $83.2(242 / 291)$ & $80.8(249 / 308)$ & & \\
\hline Took wrong drug & & & & 6.568 & 0.037 \\
\hline Yes & $5.0(19 / 380)$ & $2.7(8 / 291)$ & $1.6(5 / 308)$ & & \\
\hline No & $95.0(361 / 380)$ & $97.3(283 / 291)$ & $98.4(303 / 308)$ & & \\
\hline Stopped taking drug & & & & - & - \\
\hline Yes & $1.1(4 / 380)$ & $0.3(1 / 291)$ & $0.3(1 / 308)$ & & \\
\hline No & $98.9(376 / 380)$ & $99.7(290 / 291)$ & $99.7(307 / 308)$ & & \\
\hline Reason for missing dose & & & & & \\
\hline Forgot & $53.3(24 / 45)$ & $59.6(28 / 47)$ & $65.5(38 / 58)$ & - & - \\
\hline Afraid of being caught & $6.7(3 / 45)$ & $4.3(2 / 47)$ & $5.2(3 / 58)$ & & \\
\hline Forgot to carry & $37.8(17 / 45)$ & $29.8(14 / 47)$ & $22.4(13 / 58)$ & & \\
\hline
\end{tabular}

Note: Missing data on reason for missing dose at 1, 6,12 months were 21, 7, 3, respectively;

Patients with ART-initial CD4 cell counts $>500$ cells $/ \mathrm{mm}^{3}$ were compared to those with CD4 cell counts $<500$ cells $/ \mathrm{mm}^{3}$. There was no difference in the rate of adherence between these groups at 1-month, 6-months, or 12-months of follow-up (ARR=0.765, $95 \% \mathrm{CI}=0.476,1.230$ ). Furthermore, the study found that being over 30 years of age was protective against non-adherence to ART
(ARR=0.641, 95\%CI=0.441, 0.931), compared to being 30 years of age younger. Alcohol use was an independent risk factor for ART adherence. The risk of non-adherence among alcohol users was 1.809 times that of non-alcohol users in this group of HIV-positive MSM (ARR=1.809, 95\%CI=1.266, 2.584) (Table 3).

Table 3: Predictors of non-adherence and the effect of early ART initiation to adherence by GEE model.

\begin{tabular}{|c|c|c|c|c|c|c|c|}
\hline Variable & $\begin{array}{c}\text { Rate of non- adherence } \\
\text { (1 month) }\end{array}$ & $\begin{array}{l}\text { Rate of non- adher- } \\
\text { ence ( } 6 \text { months) }\end{array}$ & $\begin{array}{l}\text { Rate of non- adherence } \\
\text { (12 months) }\end{array}$ & $\begin{array}{c}\text { CRR } \\
(95 \% \mathrm{CI})\end{array}$ & $P$ & $\begin{array}{c}\text { ARR } \\
(95 \% \mathrm{CI})\end{array}$ & $P$ \\
\hline Age & & & & & 0.016 & & 0.019 \\
\hline \multirow{2}{*}{$0-30$} & 17.7 & \multirow{2}{*}{$21.3(43 / 202)$} & \multirow{2}{*}{$23.2(47 / 203)$} & \multirow{2}{*}{1} & & \multirow{2}{*}{1} & \\
\hline & $(44 / 249)$ & & & & & & \\
\hline \multirow[b]{2}{*}{$>30$} & 17.2 & \multirow[b]{2}{*}{$12.5(11 / 88)$} & \multirow[b]{2}{*}{$14.7(15 / 102)$} & 0.637 & & 0.641 & \\
\hline & $(22 / 128)$ & & & $\begin{array}{l}(0.441- \\
0.920)\end{array}$ & & $\begin{array}{l}(0.441- \\
0.931)\end{array}$ & \\
\hline Education & & & & & 0.159 & & 0.272 \\
\hline \multirow{2}{*}{$\begin{array}{l}\text { Senior high school and } \\
\text { under }\end{array}$} & 20.2 & \multirow{2}{*}{$11.5(10 / 87)$} & \multirow{2}{*}{$13.0(12 / 92)$} & \multirow{2}{*}{1} & & \multirow{2}{*}{1} & \\
\hline & $(23 / 114)$ & & & & & & \\
\hline \multirow{2}{*}{$\begin{array}{l}\text { Greater than senior } \\
\text { high school }\end{array}$} & 16.2 & \multirow[b]{2}{*}{$21.6(44 / 204)$} & \multirow[b]{2}{*}{$23.1(50 / 216)$} & 1.308 & & 1.239 & \\
\hline & $(43 / 266)$ & & & $\begin{array}{l}(0.900- \\
1.900)\end{array}$ & & $\begin{array}{l}(0.845- \\
1.816)\end{array}$ & \\
\hline Uses alcohol & & & & & 0.001 & & 0.001 \\
\hline
\end{tabular}




\begin{tabular}{|c|c|c|c|c|c|c|c|}
\hline \multirow{2}{*}{ No } & 16.4 & \multirow{2}{*}{$16.3(39 / 239)$} & \multirow{2}{*}{$18.3(45 / 246)$} & \multirow{2}{*}{1} & & \multirow{2}{*}{1} & \\
\hline & (51/311) & & & & & & \\
\hline \multirow[b]{2}{*}{ Yes } & 23.1 & \multirow[b]{2}{*}{$29.4(15 / 51)$} & \multirow[b]{2}{*}{$28.8(17 / 59)$} & 1.766 & & 1.809 & \\
\hline & $(15 / 65)$ & & & $\begin{array}{l}(1.247- \\
2.503)\end{array}$ & & $\begin{array}{l}(1.266- \\
2.584)\end{array}$ & \\
\hline Anal sex & & & & & 0.169 & & 0.341 \\
\hline \multirow{2}{*}{ No } & 17.9 & \multirow{2}{*}{$16.4(41 / 250)$} & \multirow{2}{*}{$20.2(51 / 252)$} & \multirow{2}{*}{1} & & \multirow{2}{*}{1} & \\
\hline & $(55 / 307)$ & & & & & & \\
\hline \multirow[b]{2}{*}{ Yes } & 16.4 & \multirow[b]{2}{*}{$32.5(13 / 40)$} & \multirow[b]{2}{*}{$21.6(11 / 51)$} & 1.301 & & 1.205 & \\
\hline & $(11 / 67)$ & & & $\begin{array}{l}(0.894- \\
1.893)\end{array}$ & & $\begin{array}{l}(0.821- \\
1.769)\end{array}$ & \\
\hline $\begin{array}{l}\text { ART-initial CD4+ cell } \\
\text { count (cells } / \mathrm{mm}^{3} \text { ) }\end{array}$ & & & & & 0.555 & & 0.269 \\
\hline \multirow{2}{*}{$\mathrm{CD} 4<500$} & 18.4 & 17.6 & 20 & \multirow{2}{*}{1} & & \multirow{2}{*}{1} & \\
\hline & $(59 / 321)$ & $(43 / 244)$ & $(51 / 255)$ & & & & \\
\hline \multirow[b]{2}{*}{$\mathrm{CD} 4>500$} & 11.9 & 23.4 & 20.8 & 0.87 & & 0.765 & \\
\hline & $(7 / 36)$ & $(11 / 47)$ & $(11 / 53)$ & $\begin{array}{l}(0.549- \\
1.380)\end{array}$ & & $\begin{array}{l}(0.476- \\
1.230)\end{array}$ & \\
\hline
\end{tabular}

\section{Discussion}

This cohort study was conducted over nearly 2 years, and the follow-up rates were $74.6 \%, 81.1 \%, 55.8 \%$ at the 6 -month, 12-month, and $>12$ months follow-up points, respectively. The most probable reason for the lower follow-up rate at $>12$ months is that this is a dynamic cohort study and some patients were only enrolled in this study for less than 1 year. No significant differences were observed for socio-demographic characteristics between five follow-up points, according to chi-square tests. The goal of this study was to describe the rate of ART adherence among HIV-positive MSM by analyzing cohort data from self-reported questionnaires. We found adherence rates to ART at 1, 6, 12, and >12 months of followup were decreased only slightly from $82.6 \%$ to $78.3 \%$, with no significant differences in these rates. This adherence rate is similar to reports of rates in other Chinese cities [16-17] and is higher than that in Zambia (59.9\%) [18]. This difference in adherence may be explained by different methods for measuring adherence, ART management models, and patient characteristics. Xixi hospital in Hangzhou is engaged in the ART management in Hangzhou, while the CDC was in charge of this work 4 years ago.

This change in management somehow decreased adherence to ART because the hospital did not receive enough support to conduct the work. However, there has recently been a slight change in adherence because the hospital received funding, and patients are now more likely to follow their doctor's suggestions and management. This is likely why the adherence rates did not change over 4 follow-up points. However, previous research has suggested that adherence should be maintained at a minimum of $95 \%$ for better viral load suppression and immune system recovery [19]. Therefore, adherence rates still need to be improved in Hangzhou.

The main reason for non-adherence in this study was missed doses $(>10 \%)$ followed by incorrect doses $(<1 \%)$ and cessation of taking ART $(<1 \%)$. The most commonly missed drugs were AZT and TDF. The most commonly reported reason for missing doses was forgetting to take the dose (almost 50\%), followed by forget to carry the drugs (22.4\%-37.8\%). The results of this study are similar to those reported by other studies [20-21]. In China, patients need to take many tablets in different bottles every day, which increases the adherence difficulty for MSM who have formal jobs. There appears to be a common belief that reminder settings, multifunctional boxes, and case management are good for methods to remind patients to take their drugs and that these methods increase ART adherence [20,22-23].

In 2013, the WHO revised the HIV treatment guidelines to state that initiating ART at a CD4 cell count threshold of 500 cells/ $\mathrm{mm}^{3}$ for HIV patients was recommended [24]. The WHO guidelines were updated in 2015 to recommend ART initiation at any CD4 cell count. China has consistently followed these guidelines, initiating ART if CD 4 cell counts were less than 500 cells $/ \mathrm{mm}^{3}$ in 2013 and initiating ART in all patients diagnosed as HIV-positive regardless of their CD4 cell count. In this study, approximately $15.5 \%$ of early diagnosed (CD4 cell count $\geq 500 /$ cells $/ \mathrm{mm}^{3}$ ) MSM received ART in Hangzhou, and this number will likely increase in the next few decades. The worldwide effect of early initiation of ART on adherence is unclear. The results of this study indicate that there is no relationship between ART-initial CD4 cell count and ART adherence among MSM, controlling for confounding factors such as age, education, alcohol use, and anal sex.

This is an important finding that demonstrates that patients initiating ART with high CD4 cell count will likely adhere to the regimen as well as patients with lower CD4 cell counts. This dynamic may be explained by the fact that patient perceptions on when to start ART can differ from their actions [25]. One study found that $78.4 \%$ of patients were willing to start ART when their 
CD4 counts were $\geq 500 /$ cells $/ \mathrm{mm}^{3}$ [25]. Additionally, in another study by our research group, we surveyed the acceptance of early ART among HIV-negative MSM in Hangzhou and found that 82.4\% MSM were willing to initiate ART at any CD4 cell count (unpublished). Furthermore, a study in South Africa has revealed that viral suppression rates at 3, 6, 12 and 18 months were above $85 \%$ with no statistically significant differences for participants stating ART at different CD4 cell counts [25].

Adherence to ART is affected by many factors [14-15,26]. In this study, other important factors relating to ART non-adherence included having an education level greater than the completion of senior high school and reporting having had anal sex in the last month. MSM have a higher level of educational and a greater knowledge of HIV than other high-risk populations [27]. Educated patients may receive more information related to initiating ART and can thus weight the drawbacks and acknowledge the benefits on an individual level [28-29]. MSM who recently had anal sex are more likely not to adhere to their ART regimen, which may be due to the inconvenience of taking the medication if they are having sex with someone [14-15,26]. This study had some limitations. First, the study population only consisted of MSM, meaning that the conclusions from this study cannot be generalized to women, children, and heterosexual men. Second, patients who participated in the study may have been more health-conscious and thus may have had better adherence, which leads to selection bias. Finally, the follow-up rate of this cohort-study at $>12$ months was less than $70 \%$, which might generate bias in the analysis. Future studies should investigate the relationship between ART initiation and initial CD4 cell counts in other populations to better inform ART programming.

\section{Conclusion}

In this cohort study, we have shown that ART adherence was high in Hangzhou. The main reason for non-adherence was missed doses and forgetting to take tablets was the most common reason for missing doses. There was no effect of ART-initial CD4 cell count on adherence in this study. Appropriate education and counseling by healthcare professionals might be good for patients who start ART early and may ensure successful therapy.

\section{Declarations}

Ethics approval and consent to participate

The study was reviewed and approved by the Ethics committee of Zhejiang Provincial Center for Disease Control and Prevention (CDC). Informed consent was signed by all subjects prior to the initiation of the study.

\section{Authors' Contributions}

Jinlei Zheng participated in the design of the study, data management, and drafted the manuscript. Lin Chen carried out data cleaning and Mingyu Luo carried out the analysis. Miaoying
Dong, Guoxiang Zheng carried out data collection. Lin He, Yun $\mathrm{Xu}$, Jiang Jun, Wanjun Chen participated in data management in different research field. Xiaohong Pan, Jianhua Yu and Jiezhe Yang performed the design and coordination of the study. All authors read and approved the final manuscript.

\section{Funding}

This study was supported by Research Project for Health and Family Planning Commission of Zhejiang Province (2014ZDA034)

The funding supported us in data collection and revision of the manuscript.

\section{Acknowledgment}

The authors thank the staff of the HIV/AIDS clinic in Xixi hospital of Hangzhou for their implementation of this research. We also thank the staff of the Hangzhou CDC for their assistance in the fieldwork. Sign flow chart for HIV/AIDS cohort study 2015-2016.

\section{References}

1. Xu Y, Pan XH, Yang JZ (2010) HIV/AIDS epidemic in Zhejiang province,1985 -2009. Disease Surveillance 25(11): 877-890.

2. Xu Y, Pan XH, Zheng JL (2017) Estimation of HIV epidemic in Zhejiang province,2015. Disease Surveillance 32(2): 118-122.

3. Wang H, Xia SC, Pan XH (2015) Investigation of HIV Infection and Impact Factors among MSM in Hangzhou. Chinese Journal of Aids\&STD 21(12): 1043-1047.

4. Yang JZ, Jiang J, Chen L (2014) An analysis of HIV sentinel surveillance among men who have sex with men in Zhejiang Province in 2010-2013. Chin J AIDS STD 20(12): 922-925.

5. Yin W, Hao Y, Sun X, Gong X, Li F, et al. (2010) Scaling up the national methadone maintenance treatment program in China: achievements and challenges. Int J Epidemiol 39(S2): 29-37.

6. Zhang FJ, Dou ZH, Ma Y, Zhang Y, Zhao Y, et al. (2011) Effect of earlier initiation of antiretroviral treatment and increased treatment coverage on HIV-related mortality in China: a national observational cohort study. Lancet Infect Dis 11(7): 516-524.

7. Zheng JL, Xu Y, He L, Jiang J, Zhang JF, et al. (2016) Analysis on antiretroviral therapy efficacy for HIV/AIDS in Zhejiang province, 20092014 Chinese Journal of Epidemiology 37(5): 673-677.

8. Maggiolo F, Airoldi M, Kleinloog HD, Callegaro A, Ravasio V, et al. (2007) Effect of adherence to HAART on virologic outcome and on the selection of resistance-conferring mutations in NNRTI- or PI-treated patients. HIV Clin Trials 8(5): 282-292.

9. Tran BX, Nguyen LT, Nguyen NH, Hoang QV, Hwang J (2013) Determinants of antiretroviral treatment adherence among HIV/AIDS patients: a multisite study. Glob Health Action 6: 19570.

10. Cohen MS, Chen YQ, McCauley M, Theresa Gamble, Mina C Hosseinipour, et al. (2016) Antiretroviral Therapy for the Prevention of HIV-1 Transmission. N Engl J Med 375(9): 830-839.

11. Donnell D, Baeten JM, Kiarie J, Thomas KK, Stevens W, et al. (2010) Heterosexual HIV-1transmission after initiation of antiretroviral therapy: a prospective cohort analysis. Lancet 375(9731): 2092-2098.

12. Chesney MA (2000) Factors affecting adherence to antiretroviral therapy. Clin Infect Dis 30 (Supplement 2): 171-176.

13. Langebeek N, Gisolf EH, Reiss P, Vervoort SC, Hafsteinsdóttir TB, et al. (2014) Predictors and correlates of adherence to combination antiretroviral therapy (ART) for chronic HIV infection: a meta-analysis. BMC Med 12(1): 142. 
14. Maqutu D, Zewotir T, North D, Naidoo K, Grobler A (2011) Determinants of optimal adherence over time to antiretroviral therapy amongst HIV positive adults in South Africa: a longitudinal study. AIDS Behav 15(7): 1465-1474

15. Zhang JH, Zhang YP, Hong H (2017) Factors associated with adherence to ART for HIV/AIDS patients in Ningbo. Chinese J Aids \& STD 23(5): 393-396.

16. Chen YX, Liu ZY, Li XM (2015) Medication adherence and influence factors for taking medications among people living with HIV/AIDS. Chinese J Aids STD 21(4): 268-272.

17. Sasaki Y, Kakimoto K, Dube C, Izukanji Sikazwe, Crispin Moyo, et al. (2012) Adherence to antiretroviral therapy (ART) during the early months of treatment in rural Zambia: influence of demographic characteristics and social surroundings of patients. Annals of clinical microbiology and antimicrobials 11(1): 34 .

18. Lima VD, Harrigan R, Murray M, Moore DM, Wood E, et al. (2008) Differential impact of adherence on longterm treatment response among naive HIV-infected individuals. AIDS 22(17): 2371-2380.

19. Yao N, Wang CF, Zhao SK (2015) Antiretroviral therapy adherence among HIV/AIDS patients in XI'an. Chin J AIDS STD 21(3): 184-188.

20. Jiamsakul A, Kumarasamy N, Ditangco R, Li PC, Phanuphak P, et al. (2014) Factors associated with suboptimal adherence to antiretroviral therapy in Asia. J Int AIDS Soc 17: 18911.

21. Dilek YS, Alper G, Ozlem AA, Bilgul Mete, Fatma Sargin, et al. (2017) Adherence to Antiretroviral Therapy in Turkey: Results from the

ISSN: 2574-1241

DOI: 10.26717/BJSTR.2019.20.003443

Jiezhe Yang. Biomed J Sci \& Tech Res

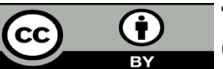

This work is licensed under Creative Commons Attribution 4.0 License

Submission Link: https://biomedres.us/submit-manuscript.php
ACTHIV-IST Study Group. AIDS Research and Human Retroviruses $33(12)$.

22. Li JW, Zhang J, Shao Y (2017) Use and effects of case management in antiretroviral therapy. Chinese Journal of Aids\&STD 23(7): 657-659

23. (2013) World Health Organization. Consolidated guidelines on the use of antiretroviral drugs for treating and preventing HIV infection: recommendations for a public health approach June 2013

24. Nigel G, Emily N, Kerry L, Naicker N, Asari V, et al. (2017) Acceptability of Early Antiretroviral Therapy Among South African Women. AIDS Behav 22(3): 1018-1024.

25. Xiao YK, Ji GP, Liu AW (2014) An analysis of adherence and its influencing factors among AIDS patients receiving ART in Anhui province. Chinese Journal of Aids \& STD 20(7): 489-491.

26. Brantley, Meredith, Schumacher, Fields EL, Perin J, Safi AG, et al. (2017) The network structure of sex partner meeting places reported by HIVinfected MSM: Opportunities for HIV targeted control. Social Sci Med 182: 20-29.

27. Fox MP, Mazimba A, Seidenberg P, Crooks D, Sikateyo B, et al. (2010) Barriers to initiation of antiretroviral treatment in rural and urban areas of Zambia: a cross-sectional study of cost, stigma, and perceptions about ART. J Int AIDS Soc 6(13): 8.

28. Zhang Q Tang Z, Sun H, Cheng P, Qin Q, et al. (2015) Acceptability of early antiretroviral therapy among HIV-infected people in Anhui province in China. AIDS Care 27(5): 669-674.

$\begin{array}{ll}\text { BIOMEDICAL } & \text { Assets of Publishing with us } \\ \text { RESEARCHES } & \text { - Global archiving of articles } \\ & \text { - Immediate, unrestricted online access } \\ & \text { - Rigorous Peer Review Process } \\ \end{array}$

